\title{
Uso de Nanopartículas de plata en el control de microorganismos patógenos presentes en alimentos
}

\author{
Using silver nanoparticles for control pathogenic microorganisms in foods
}

\author{
Villamizar G. Raquel ${ }^{1}$, Monroy P. Lucila ${ }^{2}$ \\ ${ }^{1}$ Universidad de Pamplona, Facultad de Ciencias Básicas, Km. 1 Vía Bucaramanga, Pamplona Norte de \\ Santander-Colombia \\ ${ }^{2}$ Universidad de Pamplona, Facultad de Ingenierías y Arquitectura, Km. 1, Vía Bucaramanga, Pamplona \\ Norte de Santander-Colombia
}

Recibido 07 Abril 2015; aceptado de 12 Mayo 2015

\section{RESUMEN}

En la industria de alimentos existen un sin número de microorganismos patógenos que pueden llegar al consumidor y ocasionar daños a nivel de salud pública. E. coli, S. aures, mohos y levaduras, son algunos de los microorganismos patógenos frecuentemente encontrados en frutas mínimamente procesadas. Por tal motivo, se hace necesario encontrar métodos que permitan controlar su crecimiento sobre todo en condiciones de almacenamiento previo a su consumo. En este estudio se sintetizaron nanopartículas de plata (AgNPs), a través de métodos biotecnológicos $y$, posteriormente, se emplearon en ensayos in vitro para inhibir el crecimiento microbiano. Además, bolsas de polietileno fueron modificados con una solución de AgNPs, siendo estas empleadas para el almacenamiento de frutas (tomate de árbol y uchuvas) y observar los efectos en la conservación de estos dos productos. Los resultados permitieron determinar que las AgNPs ejercen un mayor efecto microbicida sobre levaduras, seguido de bacterias Gram Negativas y último lugar, las bacterias Gram Positivas. Los ensayos en fruta permitieron determinar que las nanopartículas de plata ejercen un efecto inhibitorio de 3 a 4 unidades logarítmicas acompañado de procesos de desinfección y refrigeración.

Palabras clave: alimentos, microorganismos patógenos, nanopartículas de plata, empaques poliméricos.

\section{ABSTRACT}

*Autor a quien debe dirigirse la correspondencia. E-mail: raqvillamizar@unipamplona.edu.co
In the food industry there are a huge number of pathogens that can reach to consumers and cause damage. E. coli, S. aureus, molds and yeasts, are some of the frequently encountered pathogens in minimally processed fruits. Therefore, it is necessary to find methods to control its growth especially in storage conditions 
prior to consumption. In this study silver nanoparticles (AGNPS) were synthesized by biotechnological methods and subsequently employed in vitro assays to inhibit microbial growth. Besides polyethylene bags were modified with a solution of AGNPS and fruit (tomato and groundcherry) were stored to observe the effects of the conservation methods on these two products packaging. The results allowed determining that the AGNPS have a greater microbicide effect on yeast, followed by Gram Negative and finally, Gram Positive bacteria. Fruit trials allowed observing that silver nanoparticles exert an inhibitory effect of 3 to 4 log units together with disinfection process and cooling.

Keywords: Foods, Pathogenic Microorganisms, Silver Nanoparticles, Polymeric Packages.

\section{INTRODUCCIÓN}

Las enfermedades transmitidas por alimentos son el producto del consumo de alimentos contaminados con amplia gama de microorganismos patógenos, sus toxinas o sustancias químicas. En el año 2015, en los Estados Unidos se presentaron 9.4 millones de casos de enfermedades transmitidas por alimentos (ETAs) siendo Escherichia coli y $S$. aureus algunos de los patógenos más frecuentemente asociados (Gustafson et al., 2005). Estas bacterias tienen en común que son patógenos de humanos y animales y su mecanismo de transmisión es fecal-oral. Salmonella ha sido frecuentemente asociada a brotes por el consumo de frutas tropicales contaminadas (Ma C, 2015) mientras que $S$. aureus, es una bacteria ubicua, cuya transmisión está frecuentemente relacionada con la ingestión de alimentos preparados o manipulados inapropiadamente. En Colombia, según datos del Centro de Inspección, Vigilancia y Control (IVC), en el año 2010 se reportaron 23.009 alimentos con presencia de Staphylococcus coagulasa positiva (MPS 2010). En países tropicales como Colombia, la comercialización de frutas frescas presenta varios inconvenientes, debido al manejo de temperaturas y humedades relativas que varían de región a región, que hacen que las poblaciones microbianas inherentes al producto experimenten incrementos exponenciales haciendo que los productos se deterioren rápidamente. En este aspecto, los mohos y las levaduras aunque no son la población más numerosa en productos mínimamente procesados si son los principales agentes etiológicos asociados al deterioro generando cambios en color, aspecto entre otros (Oliveira et al., 2015). Por lo anterior, existe la necesidad de encontrar métodos que contribuyan al control de estos patógenos en alimentos ya sea durante su procesamiento, empaque y/o distribución. En este sentido, la Nanotecnología se plantea como un área multidisciplinar de la ciencia que ha ido permeando en los últimos años muchos sectores y entre ellos se encuentra el alimentario. Una de las aplicaciones más llamativas de esta tecnología se ha enfocado en la producción de empaques modificados con nanopartículas de plata (AgNPs). Materiales híbridos poliméricos (nanocomposites) con recubrimientos de nanopartículas de nanopartículas de plata confieren excelentes propiedades de conservación de alimentos (Metak et al., 2015). Esto se debe al efecto entre otras cosas, a la actividad microbicida que estas exhiben las AgNPs y a su alta estabilidad. Por tanto, a través de este estudio se emplearon nanopartículas de plata sintetizadas biotecnológicamente para inhibir y/o reducir el crecimiento microbiano in vitro y en empaques de polipropileno modificados. 


\section{Síntesis biotecnológica de nanopartículas}

Las nanopartículas de plata fueron sintetizadas siguiente el protocolo de Liu L. et al., (2014), con algunas modificaciones. Caldo malta (Merck) fue usado como sustrato para el crecimiento de $A$. flavus, hongo a partir del cual se obtuvo la solución reductora. La biomasa obtenida fue sometida a estrés nutricional con el fin de acelerar la producción de metabolitos secundarios, las cuales fueron expuestas a una solución $0.1 \mathrm{mM}$ de nitrato de plata bajo condiciones controladas de laboratorio. Las AgNPs fueron caracterizadas mediante espectrofotometría UV-VS (Thermo Electron Corporation BIOMATE 5) y su actividad microbicida fue evaluada.

\section{Aislamiento de bacterias patógenas}

S. aures, fue aislado a partir de manipuladores siguiendo el procedimiento descrito por Corrales et al., (2012). E.coli fue aislada de acuerdo a la metodología de Villamizar et al., (2015). Se emplearon medios de cultivo marca Merck preparados acorde a las especificaciones de la casa comercial. Cándida albicans fue provista por el cepario de la Universidad de Pamplona. Las bacterias fueron incubadas a $37^{\circ} \mathrm{C}$ (incubadora Memmert), mientras que Candida se incubó a $25^{\circ} \mathrm{C}$. Los microorganismos fueron caracterizados morfológica y bioquímicamente a partir de cultivos axénicos hechos en agar nutritivo.

\section{Ensayos de inhibición in vitro}

Las pruebas de actividad antimicrobiana se llevaron a cabo empleando el método de difusión en placa. Las bacterias aisladas fueron sembradas de forma masiva en cajas de Petri conteniendo agar nutritivo. Seguidamente, un sensidisco impregnado con una solución de nanopartículas de plata fue dispuesto en el centro de la caja que fue incubada durante 24 horas a $37^{\circ} \mathrm{C}$. El grado de biocontrol fue calculado midiendo los diámetros de inhibición de las AgNPs sobre los diferentes microorganismos ensayados Villamizar (2013). Los ensayos fueron hechos por triplicado.

\section{Ensayos de inhibición en fruta}

Empaques de polipropileno fueron modificados con una solución de nanopartículas de plata y se dejaron secar durante 48 horas a temperatura ambiente. Posteriormente, 11 gramos de Tomate de árbol y 13 uchuvas fueron empacadas aplicando vacío al $95 \%$ en empacadora Marca Citalsa. Las frutas fueron conservadas sin desinfectar $y$ desinfectadas (solución hipoclorito a $5 \mathrm{ppm}$ ) a temperatura ambiente y en refrigeración, con humedad relativa de $45 \%$ y $55 \%$, respectivamente. Después de tres días se realizaron análisis microbiológicos de coliformes totales, E.coli, aerobios mesófilos, mohos y levaduras.

\section{RESULTADOS Y DISCUSIÓN}

Las nanopartículas fueron sintetizadas exitosamente en 72 horas, tiempo en el cual se observó cambio en la coloración, producto de la resonancia de plasmón de los electrones superficiales de las nanopartículas (figura 1) (10). La caracterización a través de espectrometría UVVis, permitió observar la formación de picos de absorbancia a $420 \mathrm{~nm}$ característicos y que coinciden con investigaciones que han reportado valores entre $378 \mathrm{~nm}$ y $420 \mathrm{~nm}$ (11). En el proceso 56 de reducción del nitrato de plata para la formación de las nanoparticulas de plata, están vinculadas diferentes metabolitos secundarios fúngicos, específicamente, enzimas reductasa dependientes de $\mathrm{NADH}$, así mismo proteínas y polisacáridos producidos por los hongos que cumplirían una función estabilizante de coloide. 
1

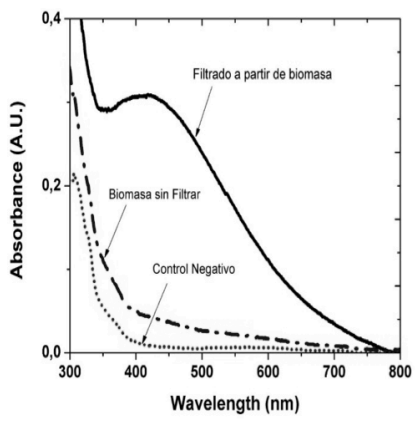

2

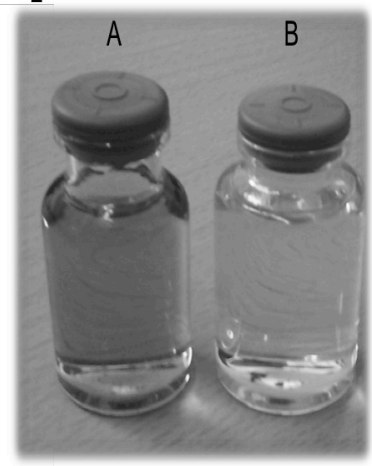

Figura 1. 1) Espectro UV-Vis de Nanopartículas de Plata sintetizadas biotecnológicamente usando $A$. flavus. 2) Solución de nanopartículas A) Producto reducido a partir de nitrato de plata B) Solución Control (Nitrato de Plata)

La actividad antimicrobiana fue demostrada a través de la formación de halos de inhibición alrededor de los sensidiscos impregnados de una solución de AgNPs. Los diámetros de inhibición oscilaron en promedio entre $9 \mathrm{~mm}, 1.3$ y $1,8 \mathrm{~cm}$ para S.aureus, E.coli y Candida albicans, respectivamente. El efecto inhibitorio se observó después de 24 horas de incubación y puede apreciarse que $C$. albicans es más susceptible a la acción de la AgNP, seguida de E.coli y $S$. aureus (figura 2). Estos resultados coinciden con lo reportado por Haytham quien empleó nanopartículas de plata obtenidas por síntesis verde usando extractos de banano, para inhibir los mismos microorganismos (Haytham et al., 2015). A diferencia del estudio mencionado, las AgNPs sintetizadas en este estudio, presentaron un gran efecto inhibitorio sobre la levadura $C$. albicans. Esto se atribuye a la afinidad existente entre los grupos proteícos y polisacarídicos presentes en la superficie de las nanopartículas y la levadura.
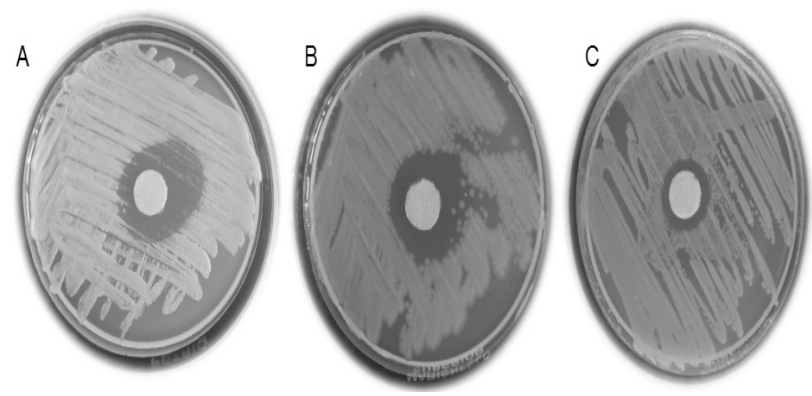

Figura 2. Efecto inhibitorio de una solución de AgNPs sobre A) Candida albicans B) E.coli C) S. aures.
Una vez se comprobó el efecto microbicida de las AgNPs a nivel in vitro, se procedió a evaluar el efecto inhibitorio en empaques de polipropileno modificados con una solución de las nanoestructuras (figura 3).
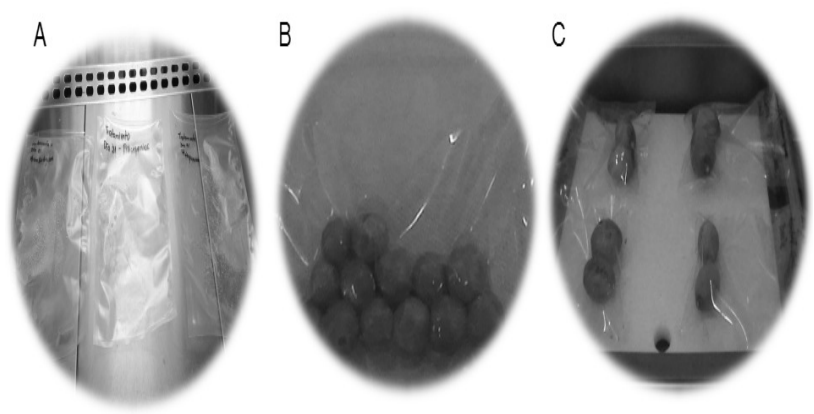

Figura 3. Evaluación del efecto inhibitorio de AgNP en empaques A) Bolsas de polipropileno modificadas con AgNPs. B) Uchuvas empacadas al vacío con AgNPs C) Tomate de Arbol empacado al vacío con AgNPs

Las frutas (tomate de árbol y uchuvas) fueron analizadas microbiológicamente antes de ser empacadas. Los resultados se muestran en la figura 4. Los recuentos coinciden con las poblaciones microbianas en frutas y verduras frescas reportadas en la literatura que oscilan entre $10^{2}$ y $10^{9} \mathrm{ufc} / \mathrm{g}$ (De Roever 1998). En ninguna de las muestras se encontraron coliformes fecales.

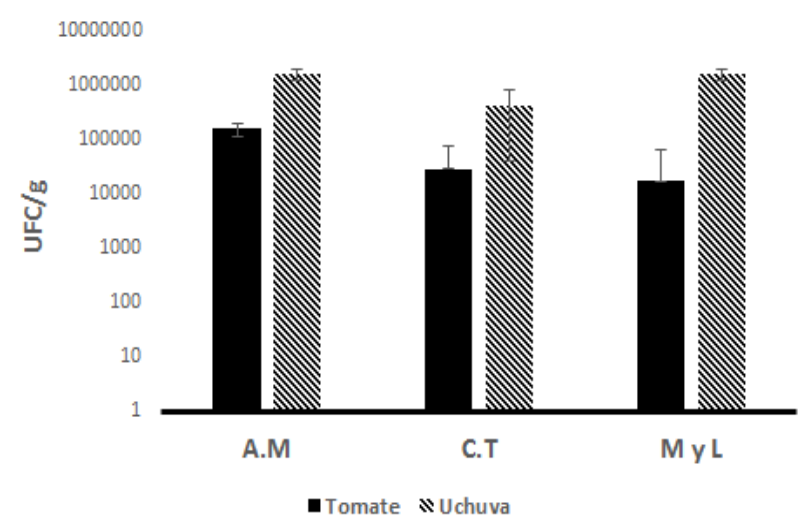

Figura 4. Comportamiento microbiológico del tomate de árbol y la uchuva antes de ser empacadas al vacío con AgNPs. AM (Aerobios Mesófilos), CT (Coliformes Totales) MyL (Mohos y levaduras).

Después de tres días de incubación, las frutas fueron valoradas microbiológicamente, con el fin de determinar el efecto inhibitorio de las nanopartículas de plata. Los resultados se 
muestran en la figura 5. Se observó que el proceso de empacado al vacío reduce considerablemente la población microbiana mesofílica. No obstante, persisten algunos debido a la permeabilidad del empaque, al oxígeno residual, ya que se trabajó un $95 \%$ de vacío y al contenido de oxígeno propio de la fruta, que favorece el crecimiento de las bacterias, mohos y levaduras autóctonas del producto. Al observar el efecto de las nanopartículas de plata, se pudo evidenciar reducciones de 2 a 4 unidades logarítmicas en las frutas sin desinfectar y desinfectadas. El efecto de inhibición más significativo (4 Log), se observó en las frutas desinfectadas, almacenadas a temperaturas de refrigeración y en empaque modificados con AgNPs, en contraste de aquellas que fueron almacenadas en empaques sin modificar.
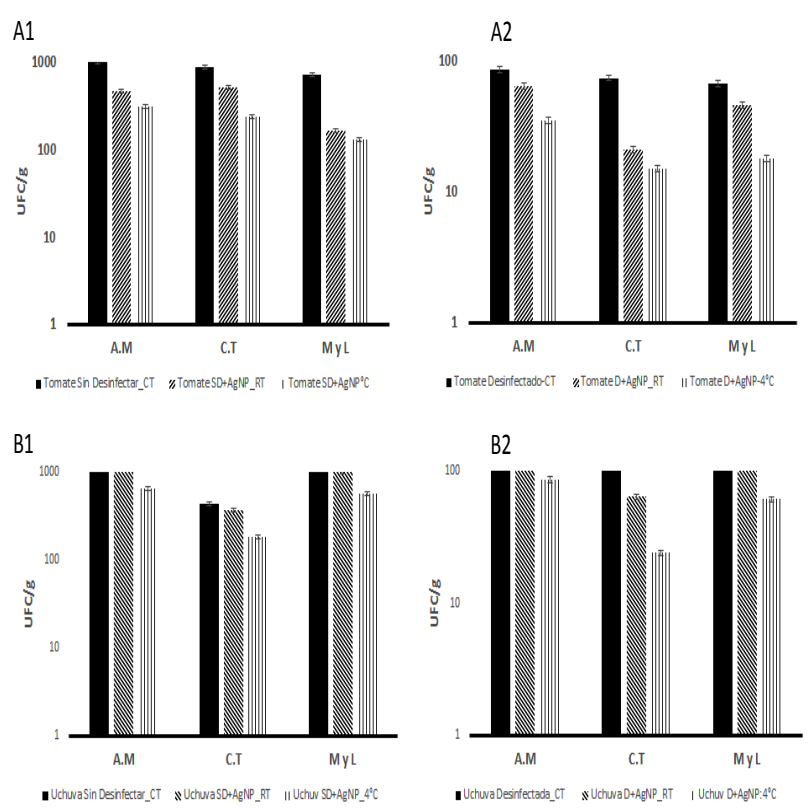

Figura 5. Comportamiento microbiológico de A1) Tomate de árbol sin desinfectar a RT y $4^{\circ} \mathrm{C} \mathrm{A2)}$ Tomate de árbol desinfectado a RT y $4^{\circ} \mathrm{C}$ B1) Uchuva sin desinfectar a RT y $4^{\circ} \mathrm{C}$ B2) Uchuva desinfectada a RT y $4^{\circ} \mathrm{C}$

\section{CONCLUSIONES}

Se demostró la capacidad que tienen las nanopartículas de plata sintetizadas biotecnológicamente de inhibir el crecimiento de microorganismos alterantes en frutas. Se comprobó además, que su efecto se ve coadyudado por el uso de bajas temperaturas y procesos de desinfección previa de la materia prima. No obstante, para llegar a una aplicación más real, se deben realizar modificaciones de los empaques más tecnificados, que eviten la migración de nanopartículas hacia los productos conservados.

\section{REFERENCIAS BIBLIOGRÁFICAS}

Gustafson J.E., Muthaiyan A., Dupre J.M., Ricke SC. Staphylococcus aureus and understanding the factors that impact enterotoxin production in foods: A review. Food Control. 2015. 1-14. doi:10.1016/j.foodcont.2014.10.016

MaC., Li J., Zhang Q. 2015.Behavior of Salmonella spp. on fresh-cut tropical fruits. Food Microbiology..1-9. In press.

MPS. Ministerio de la Protección Social de Colombia. Sistema de Inspección, Vigilancia y Control de las Direcciones Territoriales de Salud (IVC). 2010.

Oliveira M, Abadias M, Usall J, Torres R, Teixidó, Viñas I. 2015. Apllication of modifed atmosphere packaging as a safety approach to fresh-cut fruits and vegetables-A review. Trends in Food Science and Technology. 46:13-26.
Metak A.M., Nabhani F., Connolly SN. 2015. Migration of engineered nanoparticles from packaging into food products. LWT-Food Science and Technology. 64: 781-787

Liua, T, Tadea M, Wanga S, Lib X, Liu S. 2014. Less is more, greener microbial synthesis of silver nanoparticles. Enzyme and Microbial Technology. 67:53-58

Corrales L., Peña V., Caicedo DK. Identificación de Salmonella y Escherichia coli en manos y guantes de manipuladores en planta de sacrificio $y$ faenado de un municipio de Cundinamarca. Ciencias Biomédicas. 6:101-212. ISSN17942470.

Villamizar R, Darghan E, Ortíz O. 2015. Metodología rápida y sencilla para la determinación de colifagos somáticos como 
indicadores de contaminación fecal en una planta de tratamiento de agua localizada al Noreste Colombiano. Revista Universidad y Salud. 17:57-68

Villamizar R.A. 2013. Estrategias basadas en Nanotecnología para reducir la presencia de hongos en el ambiente de viviendas en fase de uso. Revista Nano Ciencia y Tecnología. 1:8-12.

Mulvaney P. Surface plasmon spectroscopy of nanosized metal particles. Langmuir. 1996. 12: 788-800
Basavaraja S, Balaji S, Lagashetty S, Rajasab V. 2008. Extracellular biosynthesis of silver nanoparticles using the fungus Fusarium semitectum. Materials Research Bulletin. 43:1164-1170

Haytham M.M. 2015. Journal of Radiation Research and Applied Sciences. 8: 265-275

De Roever, C. 1998. Microbiological safety evaluations and recommendations on fresh produce. Food Control 9: 321-347. 